\title{
Preoperative computed tomographic scanning for staging
} lung cancer

It has previously been shown that chest computed tomographic (CT) interpretations disagree with the TNM stage of lung cancer found at surgery in up to $40 \%$ of cases, ${ }^{12}$ and the article by White et al in this issue of Thorax ${ }^{3}$ presents further evidence for the limited accuracy of CT scanning (pp 951-957). It seems reasonable, therefore, to ask why - despite its overall inaccuracy - chest CT scanning remains a widely used preoperative staging modality for non-small cell carcinoma of the lung. The answer is that, provided its limitations are clearly understood, chest CT scanning provides significant help in patient management for specific groups of patients.

Knowing that a tumour is totally surrounded by aerated lung and that no central lymph node enlargement or distant spread is visible on chest CT scans can be of value. Even though this information does not directly change the management, it does allow the surgeon or chest physician to discuss the prospect of surgery with the patient in simple straightforward terms, so making it easier for the patient to participate in an informed discussion about his or her management, and to await surgery with less apprehension than if the decision was based primarily on clinical and plain radiographic findings. Also, the surgeon can embark on resective surgery with a greater degree of confidence that the correct action is being taken.

Even though it is well established that normal sized intrathoracic lymph nodes - that is, nodes with a short axis diameter of less than $10 \mathrm{~mm}$ - may harbour metastases, resective surgery without a properative biopsy can often be undertaken in patients whose tumours are confined to the lung and who have no enlarged mediastinal lymph nodes. The rationale for this course of action is that, since the nodes in question are not enlarged, a preoperative biopsy will necessarily be random and therefore sampling error will lead to a low yield. The findings of microscopic nodal metastases in nodes of normal size in some patients who undergo thoracotomy has to be accepted as inevitable with currently available investigations. The important point is that relatively few patients will be subjected to simple open and close thoracotomy.

Determining preoperatively that a tumour is irresectable has a clearcut impact on patient management because resective surgery is then not offered. However, denying a patient surgery, when the only known cure for lung cancer is surgical excision, is a heavy responsibility and is a decision that should only be taken if there is solid evidence to indicate inoperable spread of tumour. Several studies have been undertaken to investigate the accuracy of CT scanning in determining irresectability of bronchial carcinoma including the paper by White et al in this issue of Thorax. ${ }^{3}$. Unfortunately these articles usually conclude with the signs indicating resectability - information which does not change management since it is a general truism that all patients are considered for surgery unless unequivocal contraindications are identified. In order to avoid open and close thoracotomies clearcut criteria for irresectability are required. Validating the criteria for irresectability is much more difficult than appears at first sight, however; to do so would require a large number of patients with irresectable disease to uridergo thoracotomy. Because surgeons are, quite rightly, reluctant on ethical grounds to proceed with thoracotomy when the interpretation of the CT scan is highly suggestive of irresectable disease, the published series consist predominantly of patients classified as having indeterminate stage III disease. The general conclusion is that, for patients shown by CT scanning to have enlarged mediastinal nodes or probable mediastinal invasion, the correlation with the findings at surgery is poor. For example, White et $a l^{\beta}$ sum up by saying "CT scanning used as the sole method of staging is of limited value for differentiating between stage I/II and stage III tumours. Patients should not be denied the opportunity for curative surgery on the basis of equivocal CT signs". But what are the unequivocal signs of irresectability?

Currently, the only useful imaging sign of hilar/mediastinal lymph node metastases is enlargement. Neither CT density nor magnetic resonance imaging (MRI) signal intensity have proved reliable in determining or excluding metastatic involvement and gallium- 67 radionuclide imaging is too insensitive and non-specific to be a routine staging test. Hope has been expressed recently that positron emission tomography with fluoro-deoxy-glucose may provide more reliable information than $\mathrm{CT}$ scanning, ${ }^{4-6}$ but whether this proves to be the case in the long run remains to be seen.

The documented sensitivity and specificity of CT scanning for diagnosing lymph node metastases varies greatly according to the country of origin (previous fungal disease, notably histoplasmosis, in North America is a frequent incidental cause of lymph node enlargement) and the methods used to confirm the CT interpretations. As so often happens following the introduction of a new imaging technique, the early results appeared highly encouraging but when more formal studies were undertaken, including thorough sampling of all nodes whether or not they were enlarged, the accuracy proved to be much poorer. For example, early papers ${ }^{7-9}$ suggested sensitivities above $85 \%$ with acceptable specificity for diagnosing lymph node metastases. Nowadays, with more accurate pathological correlation, a reasonable generalisation is that in the USA both sensitivity and specificity are in the 50-60\% range when the cutoff point for normal is a short axis diameter of $1 \mathrm{~cm} .^{1011}$ Better specificity figures have been obtained in Europe ${ }^{12}$ and Japan, ${ }^{13}$ presumably because the pre- 
valence of coincidental fungal disease is much lower than in the USA.

In the case of lymph node enlargement it is not vital to define an unequivocal cutoff point between involved and uninvolved lymph nodes, because it should be standard practice to take biopsy specimens preoperatively from the largest most accessible lymph node using the CT scan as a guide both to select the method of biopsy and to decide which nodes to sample. Mediastinoscopy provides access to the paratracheal nodes, proximal tracheobronchial nodes, and upper subcarinal nodes. The other nodal sites require alternative approaches such as anterior mediastinotomy, needle aspiration biopsy under image guidance, or transbronchoscopic biopsy. General experience shows that very large nodes - for example, those that are $3.0 \mathrm{~cm}$ or greater in short axis diameter - are highly likely to be involved by tumour (except, perhaps, in patients who have lived in parts of the world where histoplasmosis is endemic), but fortunately biopsy specimens can almost invariably be obtained from such large nodes using a relatively noninvasive needle aspiration technique.

Chest wall invasion does not necessarily preclude surgical removal, although it does adversely affect the subsequent prognosis. Diagnosing chest wall involvement by a tumour is unreliable by CT scanning, unless there is bone destruction or a large soft tissue mass. ${ }^{14-17}$ Contact with the pleura on CT examination, even if the pleura is thickened, does not necessarily indicate invasion, although the greater the degree of contact and the greater the pleural thickening, the more likely it is that the parietal pleura has been invaded, particularly if the extrapleural fat plane is obliterated. ${ }^{18}$ Conversely, a clear extrapleural fat plane adjacent to the mass may be helpful, but again not definitive, in excluding chest wall invasion. ${ }^{17}$

Magnetic resonance imaging suffers from similar problems to CT scanning in diagnosing chest wall invasion. ${ }^{19}$ In some series, however, MRI was better than CT scanning for demonstrating chest wall and diaphragm invasion. ${ }^{2021}$ MRI scanning is now regarded as the best imaging modality for demonstrating the extent of superior sulcus tumours, largely because the coronal and sagittal planes are optimal for demonstrating the cupula shape of the chest wall in the apical regions, and for showing the brachial plexus and subclavian vessels to advantage. ${ }^{22-26} \mathrm{Rib}$ destruction, however, may be less well shown by MRI than by CT scans.

A recent report ${ }^{27}$ suggests that transthoracic ultrasonography can be an accurate method of identifying chest wall invasion when two of the following three findings are present: (a) disruption of the pleura, (b) extension into the chest wall, and (c) fixation of the tumour during breathing.

The most difficult issue when staging the intrathoracic spread of non-small cell lung cancer is deciding whether direct mediastinal invasion is present, particularly whether the degree of invasion suggests irresectability - that is, a T4 tumour, making the tumour stage III B or worse. If thoracotomy is undertaken for a $\mathrm{T} 4$ tumour the result is an open and close procedure. It has become increasingly clear that it is often difficult to differentiate on the CT scan between contact with the mediastinum but no transgression of the pleural space (T2) and minor mediastinal invasion but technically resectable disease (T3). It is even more difficult to differentiate between resectable mediastinal invasion (T3) and irresectable mediastinal tumour (T4).

Based on a retrospective study of 80 patients with tumours categorised by CT scanning as indeterminate for mediastinal invasion who were subsequently operated upon, Glazer $e t a l^{28}$ suggested that a tumour is likely to be technically resectable - that is, stage $\mathrm{T} 3$ or less - if one or more of the following features are present: (a) less than $3 \mathrm{~cm}$ of contact with the mediastinum; (b) less than $90^{\circ}$ circumferential contact with the aorta; or (c) a visible mediastinal fat plane between the mass and any vital mediastinal structures. Thirty six of 37 masses in their series conformed to this description and proved to be technically resectable (28 with no mediastinal invasion and eight with mediastinal invasion). However, there is significant difficulty when the question is turned around to ask: what are the criteria for irresectability? ${ }^{29}$ (This, as emphasised earlier, is the important question because, if the distinction could be made accurately, many patients would be spared unnecessary exploratory thoracotomy.) In the series by Glazer et $a l^{8}$ more than $3 \mathrm{~cm}$ of contact with the mediastinal surface was present in almost half the tumours that proved resectable and no visible fat plane was seen between the tumour and a major mediastinal structure in most resectable tumours.

Magnetic resonance imaging does not currently appear to offer any advantages over CT scanning in the routine diagnosis of mediastinal invasion. It is generally no more accurate than CT scanning in distinguishing between contiguity of tumour with the mediastinum and mediastinal invasion, largely because invasion of the mediastinal fat can be mimicked by adjacent inflammatory changes. ${ }^{192030}$ MRI can, however, provide unique information in certain circumstances ${ }^{1920231-35}$ - for example, it is clearly superior to CT scanning for identifying involvement of major mediastinal blood vessels. Endobronchial tumour extension remains the province of bronchoscopy, but extraluminal bronchial encasement is well seen on coronal MRI scans.

In summary, the major signs of $\mathrm{T} 4$ neoplasm by both CT scanning and MRI are visible tumour surrounding mediastinal vessels, oesophagus, or proximal main stem bronchi. Mere contact with the mediastinum is not enough for the diagnosis of invasion and even apparent interdigitation with mediastinal fat on either CT or MRI scans does not necessarily mean the tumour is irresectable. Associated pneumonia or atelectasis add considerably to the diagnostic difficulty. Currently, therefore, the surgeon is faced with the regrettable fact that, in patients with suspected direct mediastinal invasion, some open and close thoracotomies are inevitable if all patients with potentially resectable lung cancers are to be offered surgery.

Academic Department of Radiology,

P ARMSTRONG St Bartholomew's Hospital,

London EC1A $7 B E$

1 Lewis JW, Pearlberg JL, Beute GH, Alpern M, Kuale PA, Gross BH. Can computed tomography of the chest stage lung cancer? Yes and no. $A n n$ Thorac Surg 1990;49:591-6.

2 Lahde S, Paivansalo $M$, Rainio P. CT for predicting the resectability of lung cancer: a prospective study. Acta Radiol 1991;32:449-54.

3 White PG, Adams H, Crane MD, Butchart EG. Preoperative staging of carcinoma of the bronchus: can computed tomographic scanning reliably identify stage III tumours? Thorax 1994;49:951-7.

4 Singh SK, Buonocore E, Hubner KF, Gould HR, Cotten DW. Quantitative F-18 FDG-PET for diagnosis and staging of chest tumors. Radiolog 1992;185(Suppl):324-5.

5 Wahl RL, Quint LE, Orringer M, Meyer $\mathrm{CH}$. Staging non-small-cell lung cancer in the mediastinum: comparison of FDG-PET, CT and hybrid "ancer in the mediastinum: comparison of FDG-PET, CT and hybrid 185(Suppl):324.

6 Wahl RL, Quint LE, Greenough RL, Meyer CR, White RI, Orringer MB Staging of mediastinal non-small lung cancer with FDE PET, CT and fusion images: preliminary prospective evaluation. Radiology 1994;191: 371-7.

7 Baron RI, Levitt RG, Sagel SS, White MJ, Roper CL, Marbarger JP. Computed tomography in the preoperative evaluation of bronchogenic carcinoma. Radiology 1982;145:727-32.

8 Lewis JW, Madrazo BL, Gross SC. The value of radiographic and computed tomography in the staging of lung carcinoma. Ann Thorac Surg 1982;34: 553-8.

9 Osborne DR, Korobkin M, Ravin CE, Putman CE, Wolfe WG, Sealy WC et al. Comparison of plain radiography, conventional tomography and computed tomography in detecting intrathoracic metastases from lung carcinoma. Radiology 1982;142:157-61.

10 McLoud TC, Bourgouin PM, Greenberg RW, Kosiuk JP, Templeton PA 
mediastinum with CT by correlative lymph node mapping and sampling. Radiology 1992;182:319-23.

11 Webb WR, Gatsonis C, Zerhouni EA, Heelan RT, Glazor GM, Francis IR, et al. CT and MR imaging in staging non-small cell bronchogenic carcinoma: report of the Radiologic Diagnostic Oncologic Group. Carcinoma: report of the

12 Buy JN, Ghossain MA, Poirson F. Computed tomography of mediastinal lymph nodes in nonsmall cell lung cancer: a new approach based on the lymphatic pathway of tumour spread. $\mathcal{f}$ Comput Assist Tomogr 1988;12: 545-52.

13 Ikezoe J, Kadowaki K, Morimoto S. Mediastinal lymph node metastases from non small cell bronchogenic carcinoma: reevaluation with CT. $\mathcal{F}$ Comput Assist Tomogr 1990;14:340-4.

14 Glazer HS, Duncan-Meyer J, Aronberg DJ, Moran JF, Levitt RG, Sagel SS. Pleural and chest wall invasion in bronchogenic carcinoma: CT SS. Pleural and chest wall invasion

15 Pearlberg JL, Sandler MA, Beute GH. Limitations of CT in evaluation of neoplasms involving chest wall. f Comput Assist Tomogr 1987;11:290-3.

16 Pennes DR, Glazer GM, Wimbish KH, Gross BH, Long RW, Orringer $\mathrm{MB}$. Chest wall invasion by lung cancer: limitations of CT evaluation. AfR 1985;144:507-11

17 Scott IR, Muller NL, Miller RR, Evans KG, Nelems B. Resectable stage III lung cancer: CT, surgical and pathologic correlation. Radiology 1988; 166:75-9.

18 Ratto GB, Piacenza G, Frola C, Musante F, Serrano I, Giua R, et al. Chest wall involvement by lung cancer: computed tomographic detection and wall involvement by lung cancer: computed tomographic
results of operation. Ann Thorac Surg 1991;51:182-8.

19 Mayr B, Lenhard M, Fink U, Heywang-Köbrunner SH, Sunder-Plassmann L, Permanetter W. Preoperative evaluation of bronchogenic carcinoma: value of MR in T- and N-staging. Eur $\mathcal{F}$ Radiol 1992;14:245-51.

20 Musset D, Grenier P, Carette MF, Frija G, Hauuy MP, Desbleds MT, et al. Primary lung cancer staging: prospective comparative study of MR imaging with CT. Radiology 1986;160:607-11.

21 Padovani B, Mouroux J, Seksik L, Chanalets S, Sedat J, Rotomondo C, et al. Chest wall invasion by bronchogenic carcinoma: evaluation with MR imaging. Radiology 1993;187:33-8.

22 Castagno AA, Shuman WP. MR imaging in clinically suspected brachial plexus tumor. $A f R$ 1987;149:1219-22.
23 Gefter WB. Magnetic resonance imaging in the evaluation of lung cancer. Semin Roentgenol 1990;25:73-84.

24 Heelan RT, Demas BE, Caravelli JK, Martini N, Bains MS, McCormack PM, et al. Superior sulcus tumours: CT and MR imaging. Radiology 1989; 170:637-41.

25 McLoud TC, Filton RB, Edelman RR, Shepard JO. MR imaging of superior sulcus carcinoma. F Comput Assist Tomogr 1989;13:233-9.

26 Takasugi JE, Rapoport S, Shaw C. Superior sulcus tumors: the role of imaging. F Thorac Imag 1989;4:41-8.

27 Suzuki N, Saitoh T, Kitamura S. Tumor invasion of the chest wall in lung cancer: diagnosis with US. Radiology 1993;187:39-42.

28 Glazer HS, Kaiser LR, Anderson DJ, Molina PL, Emami B, Roper CL, et al. Indeterminate mediastinal invasion in bronchogenic carcinoma: CT evaluation. Radiology 1989;173:37-42.

29 McLoud TC. CT of bronchogenic carcinoma: indeterminate mediastinal invasion (editorial). Radiology 1989;173:15-16.

30 Stiglbauer R, Schurawitzki H, Klepetko W, Kramer J, Shratter M, Tscholakoff $\mathrm{D}$, et al. Contrast-enhanced MRI for the staging of bronchogenic carcinoma: comparison with CT and histopathologic staging preliminary results. Clin Radiol 1991;44:293-8.

31 Laurent F, Drouillard J, Dorcier F. Bronchogenic carcinoma staging: CT vs MR imaging: assessment with surgery. Eur $\mathcal{f}$ Cardiothorac Surg 1988; 2:31-6.

32 Levitt RG, Glazer HS, Roper CL, Lee JKT, Murphy WA. Magnetic resonance imaging of mediastinal and hilar masses: comparison with $\mathrm{CT}$ resonance imaging of

33 Martini N, Heelan R, Westcott J, Bains MS, McCormack P, Caravelli J, et al. Comparative merits of conventional computed tomographic and magnetic resonance imaging in assessing mediastinal involvement in surgically confirmed lung carcinoma. $\mathcal{F}$ Thorac Cardiovasc Surg 1985;90: 639-48.

34 Webb WR, Gatsonis C, Zerhouni EA, Heelan RT, Glazer GM, Francis IR, et al. CT and MR imaging in staging non-small cell bronchogenic carcinoma: report of the Radiologic Diagnostic Oncologic Group. Carcinoma: report of the

35 Webb WR, Jensen BG, Sollitto R, de Geer G, McCowin M, Gamsu G, et al. Bronchogenic carcinoma: staging with MR compared with staging with CT and surgery. Radiology 1985;156:117-24. 